\title{
A Stochastic Method for Prediction of the Power Demand at High Rate EV Chargers
}

\begin{tabular}{|r|l|}
\hline Journal: & IEEE Transactions on Transportation Electrification \\
\hline Manuscript ID & TTE-Reg-2018-02-0040 \\
\hline Manuscript Type: & Regular Paper \\
\hline Date Submitted by the Author: & 20 -Feb-2018 \\
\hline Complete List of Authors: & $\begin{array}{l}\text { Hilton, George; University of Southampton Faculty of Engineering and the } \\
\text { Environment, Mechanical Engineering } \\
\text { Kiaee, Mahdi; University of Southampton Faculty of Engineering and the } \\
\text { Environment, Mechanical Engineering } \\
\text { Bryden, Thomas; University of Southampton Faculty of Engineering and } \\
\text { the Environment, Mechanical Engineering } \\
\text { Dimitrov, Borislav; University of Southampton Faculty of Engineering and } \\
\text { the Environment, Mechanical Engineering } \\
\text { Cruden, Andrew; University of Southampton Faculty of Engineering and the } \\
\text { Environment, Mechanical Engineering } \\
\text { Mortimer, Alan; Wood PLC }\end{array}$ \\
\hline Keywords: & \begin{tabular}{l} 
Vehicles, Battery chargers, Power system modeling, Load modeling \\
\hline
\end{tabular} \\
\hline
\end{tabular}


1

2

12

4

5

6

7

8

10

11

12

13

14

15

16

17

18

19

20

21

22

23

24

25

26

28

29

30

31

32

33

34

35

36

39

40

41

42

43

44

45

46

47

48

49

50

51

57

58

59

60 


\title{
A Stochastic Method for Prediction of the Power Demand at High Rate EV Chargers
}

\author{
George Hilton, Mahdi Kiaee, Thomas Bryden, Borislav Dimitrov, \\ Andrew Cruden and Alan Mortimer
}

\begin{abstract}
High rate $(<100 \mathrm{~kW})$ electric vehicle chargers (HREVCs) are crucial for achieving the benefits of reduced $\mathrm{CO}_{2}$ and particulate emissions promised by electric vehicles by enabling journey distances greater than the range of the vehicle. A method for predicting the expected demand pattern at these HREVCs is presented in this paper. This is critical to planning a network of chargers. This novel method uses freely available traffic flow data and travel patterns extracted from the open street map combined with a novel EV battery capacity prediction method, to find future HREVC usage patterns in the UK and their dependence on location and EV characteristics. This planning method can be replicated to find HREVC power demand for any location on the strategic road network in the UK and can be used in analysis of the role of high rate EV charging in the wider energy system.
\end{abstract}

\section{Index Terms}

Vehicles, Battery chargers, Power system modeling, Load modeling

\section{INTRODUCTION}

The use of fossil fuel vehicles contributes to climate change through the release of $\mathrm{CO}_{2}$, nitrous oxides and unburnt hydrocarbons, and causes harmful levels of pollution to be present in cities around the world [1]. The removal of fossil fuels from the transport industry is therefore of clear importance. One method to achieve this which is currently gaining traction is the introduction of electric vehicles (EVs). EVs have the advantage of zero local gaseous emissions and improved

George Hilton, Mahdi Kiaee, Thomas Bryden, Borislav Dimitrov and Andrew Cruden are with the Faculty of Engineering and the Environment, University of Southampton, University Road, Southampton, SO17 1BJ, UK

Alan Mortimer is with Wood PLC. 
drive train efficiency leading to lower levels of pollution in areas of high traffic density and lower system carbon emissions [2] [3].

A growing EV fleet in operation in the UK will necessitate investment in charging infrastructure. The development of a network of fast chargers will enable increased use of EVs and promote wider adoption through reducing range anxiety among both potential and current EV owners [4]. High rate charging of EVs allows for journey lengths greater than the range of the EV and enable EV charging for those without a domestic or workplace charging facility. Therefore, high rate electric vehicle chargers (HREVCs) will become a crucial part of the transport system in coming years.

Care must be taken to ensure the roll out of these HREVCs is completed in an efficient and successful way such that to minimise journey times and queueing [5]. An HREVC must be designed with knowledge of the expected EV charge demand both at the current time and in the future such that HREVCs are still adequate for the demand throughout their expected life [6] [7]. For this a model which predicts EV demand based on location and includes factors to allow for growing EV penetrations and reducing battery costs is needed. The model in this paper provides a basis for HREVC designers to select a location, an EV penetration level and a battery price factor and generate the power demand that that HREVC will be subject to.

The open street map is a map of the world which is free to use and operates under an open license [8]. It has a feature which allows users to upload GPS tracks of movements which has, over time, created a large repository of information relating to people's movements with 848,062 uploaded tracks. This repository has received little academic interest, however, the information it holds could provide critical insight for many fields of work. It is the aim of the authors to use this repository in order to find travel patterns along main roads in the UK to enable a prediction of HREVC demand. Specifically, detailed traffic count data is widely available for many roads in the UK. This is not adequate for predicting HREVC use as the distance of each journey being counted is not known. However, the open street map can be used to find journey distance patterns which can then be added to the existing traffic count data. This enriches the existing data resource and allows for more accurate HREVC use predictions.

The use of this analysis is combined with a predictive model of EV battery capacity in a scenario where the EV market has achieved balance, i.e. the number of different EVs being offered for sale and the rate at which they are bought and used reflects that of conventional vehicles in operation currently. This is an important step as the EV market is currently skewed 
with a disproportionately large number of luxury vehicles due to the popularity of the vehicles produced by [9], therefore, the current distribution of EVs cannot be used to predict future HREVC use. When EV adoption is widespread, this skew will not be accepted by consumers, therefore a method is needed to predict future EV battery capacities. The EV battery capacity distribution is important in finding the expected energy demand at a HREVC as larger capacity EVs will require higher power and longer charging duration, whereas lower capacity EVs will require more frequent charging for the same journey.

Therefore, in this paper, a method is presented which uses freely available data and is able to predict the HREVC demand at any location on the strategic road network (SRN) in the UK for the assumed scenario of a balanced EV fleet in the UK.

\section{A. Background}

The expected time distribution of low rate EV charging has been extensively examined in the literature as well as smart techniques which can be used to reduce grid stress [10] [11] [12]. A common method of analysis is using a probability distribution of EV use, such that charging can be predicted for when an EV is not in use [13]. This is an effective technique for low rate charging since, due to the duration, low rate $(7 \mathrm{~kW})$ "level 2 " charging is likely to occur when an $\mathrm{EV}$ is parked and the owner is conducting another activity.

The use case of HREVCs differs from that of level 2 chargers since they are designed to be used when the range of the EV is not high enough for the distance of the journey being undertaken. The Department for Transport Travel Survey reveals trip distance for private vehicles in the UK [14]. $80 \%$ of all trips are less than 10 miles in distance. However, these trips only represent $26 \%$ percent of the distance covered. Contrasting this to the use of the SRN, which accounts for all the high demand roads in the UK, such as motorways and large A-roads, it is clear that the distances covered using these roads are substantially higher per trip. Unfortunately, details given in [14] regarding long distance journeys are inadequate for this study as journey distances and the type of road used are needed. Since HREVC use will predominantly be during a long trip, it follows that HREVCs should be located on large roads such as those in the SRN. Therefore, in this paper, the assessment of traffic patterns and journey distances is calculated for journeys which use the SRN.

The literature addressing the problem of predicting EV demand at HREVCs is quite limited. Many studies assume demand will be proportional to traffic flow measurements [15], [16] or 
"mobility" measurements for urban areas [17]. These prediction methods give a characteristic two peak EV demand profile, with EVs more likely to visit an HREVC in the morning and the evening, aligning with the high use times for the road network. This approach has the clear flaw of not taking into account the distance of the journey which the EV is undertaking, an important predicting factor for HREVC use.

Another method for predicting HREVC use is to liken the HREVC demand to ICE demand for fuel [18]. This gives a demand shape similar to the studies assuming charge demand proportional to traffic flow, with a slight increase through the middle of the day. Whilst this is more realistic than assuming proportionality with traffic flow, the use of an HREVC will be different to that of a fuel station. The main difference is that there is no option to refill an ICE vehicle whilst it is parked overnight, whereas this is commonplace amongst EVs and therefore will change the required high rate charge demand. Due to this, and the extended range of ICE vehicles, their users must use refuelling stations on a more ad-hoc basis, as and when the car is in use and the fuel tank becomes empty.

In additions to these methods vehicle usage data has been previously used to predict HREVC demand. A number of vehicle GPS data studies suitable for this have been found through the National Renewable Energy Laboratory's (NREL) Secure Transportation Data Project [19]. In particular a study with real-world driving times, speeds, and distances collected from the Puget Sound Regional CouncilâĂŹs 2008 Traffic Choices Study was used in [20], [21] and [22]. This study comprised of installing GPS devices on 400 vehicles between April and June 2005, resulting in measured 149,000 trips. [21] and [22] were concerned mainly with calculating the necessary battery size for EVs to enable the mobility levels seen in the dataset. [20] uses this data to predict HREVC demand. This study assigns EVs to the usage patterns of vehicles in the study and initiates an HREVC session whenever the range of that EV is depleted through driving, with no consideration for the location or availability of an HREVC. As this study is based in real world data it can be assumed to be the most accurate in the literature. However, each EV is assigned either $16 \mathrm{kWh}$ or $40 \mathrm{kWh}$ of battery capacity which does not reflect the EVs either currently on the road or those expected in the future and is a major simplification. Additionally, in the real world HREVC locations are set and as such, a charge session occurring only when the range is fully depleted is not reflective of real-world driving conditions. The demand pattern generated by [20] is different to the other two, as it shows a demand peak in the evening, with a relatively small demand in the morning. Thus, a move away from a two peak demand pattern 
is seen when journey distance and overnight $\mathrm{EV}$ charging are taken into account.

Within this paper the authors build on the work by [20] by adopting a similar approach, however addressing the shortcomings highlighted above. The data used is not relevant to this study, though, as it is based on driving in the USA which differs from the in the UK due to differing lifestyle and geography patterns.

Alternative UK travel data is sought for the work in this paper from freely available GPS tracks on the [23]. This is then used to add details, such as journey distance, to existing traffic flow data.

Two novel contributions of the work presented in this paper are:

1) A method is proposed for predicting EV battery capacity distributions in a future scenario when the EV market reflects the use and purchase patterns currently seen with conventional vehicles.

2) A method for predicting HREVC power demand patterns in a locationally dependent way at any location on the SRN in the UK is explained.

\section{B. Assumptions used in this work}

Any modelling approach must be based on assumptions about this system which is attempting to be modelled. In this paper, there are two on which the work is based.

Firstly, it is predicted that EVs will be used in the same manner as conventional vehicles today. This accounts for two specific assumptions, firstly that the proportion of EVs within each segment (i.e. mini cars, small cars etc) is the same as that for conventional vehicles. Secondly, the journeys made by EVs will be the same as those made with conventional vehicles. Ceteris paribus, this assumption is thought to be valid as the motivations for buying and using a vehicle are technology agnostic i.e. a vehicle user needs to go from one location to another at a certain time, this need is not dependent on the type of vehicle which is used to provide this transportation need. This assumption was examined by [24] where EV trials revealed the similar use patterns to conventional vehicles with the exception of long distance journeys. The range of EVs has increased substantially since this work was published, which suggests that similar use patterns will now extend to journeys of longer distance. This assumption has been used in many works (e.g. [25] [26] [21] [27]) and discussed in greater detail by [28].

Secondly, psychological factors which may affect EV use are not considered in this paper. This assumption is made in order to maintain simplicity in the simulation. There are two likely 
implications of this. Firstly, it is assumed that there is no link between the type of vehicle being used and the journey it takes. The matching between generated EVs and journey distance is entirely random in this method. Therefore psychological factors such as "I use my EV for a lot of long distance journeys, so I will buy an EV with a high range" are not considered. Secondly, it is assumed that the driver will use the last feasible HREVC prior to the EV SOC reaching zero. Therefore, any fear associated with having a low SOC leading to earlier charging is not considered, neither is a charging method designed to save money and time by arriving at the destination at or close to zero SOC. Linked to this, the EVs are each charged to $100 \%$ usable SOC when visiting the HREVC, thereby eliminating any preference the driver may have.

\section{METHOD}

\section{A. Overview}

The five main steps within the method presented in this paper are as follows:

1) Extraction of relevant journeys from Open Street Map GPS Track Dump. Detailed in Section II-B1. Assumed to be those journeys which intersect with the SRN.

2) Prediction of journey distances for each hour of the day. This will be achieved through fitting probability distributions to extracted journeys. The aim of this process is to create a probability distribution for each hour of the day which can be used to predict the distance of a given journey which has its mid point (in time) within that hour. This information can be used to find the time of arrival at the HREVC and estimate the EV's State of Charge (SOC) at arrival. This is detailed in Section II-C.

3) Production of locationally dependent probability distributions of journey distance. This is achieved through scaling the probability distributions to the traffic flow observed at the chosen site. This is detailed in Section $\amalg-D$.

4) Prediction of battery capacities of the EVs which will use the HREVC. This is needed to find the energy demand for a given EV if the initial and final SOCs are known (through use of probability distributions created in steps 2 and 3 above). This is achieved through probability distributions fitted to characteristics in the current conventional vehicle fleet in order to predict a future case where EV ownership is widespread. This is discussed in Section $\amalg-\mathrm{E}$.

5) Execution of Stochastic Simulation. In this step, random numbers are generated from the probability distributions. In this way, an EV is given a battery capacity, a journey distance 
and a departure time. This information is then used to calculate the HREVC demand. This is detailed in Section $\amalg-\mathrm{F}$

\section{B. The Open Street Map}

The Open Street Map [8] is an online, open source map which is under an open licence, hence, anybody can make changes to it. Crucially for this work, it also has the capability for anyone to upload GPS journey traces onto it. This has led to a dataset consisting of 848,062 journeys which are available to download. These tracks cover all aspects of daily movement of the uploader, as such a method of filtering the relevant journeys is needed.

1) Data Mining Approach: As the dataset is large, a data mining approach was utilised to find relevant GPS traces. The aim of this approach was to identify all the traces which overlapped with the SRN. As very little walking or cycling is conducted on the SRN it is assumed that each GPS trace which intersects with it is a vehicle journey.

The strategic road network is managed by Highways England. A shapefile describing the land managed by Highways England is available as an open source download from the UK Government repository [29]. This is shown in Figure 11.

Each journey within the dataset consists of a number of GPS points, with a timestamp. As the timestamps follow in chronological order, these points can be joined to form a trace. A number of example journeys are shown in Figure 2.

Individually assessing each point on each GPS trace to determine whether it lays within the bounds of the SRN shapefile would have been far too computationally intensive. As such, a box was constructed for each GPS trace, the edges of which lay at the furthest bounds of the journey, this box is then assessed for intersection with the SRN shapefile. This reduced the computational time substantially. An schematic example of this method is shown in Figure 3.

After running this data mining procedure on the dataset, the number of relevant journeys on the SRN was found to be 2287.

\section{Constructing probability distributions from mined data}

The aim of using the Open Street Maps GPS tracks was to create probability distributions of journey distance. In order to achieve this, the filtered GPS tracks were split into distinct arrays dependent on the mid point in time for that journey. This gave 24 datasets each corresponding to the previous hour. Journeys with distance of less than 1 mile were removed as they were 


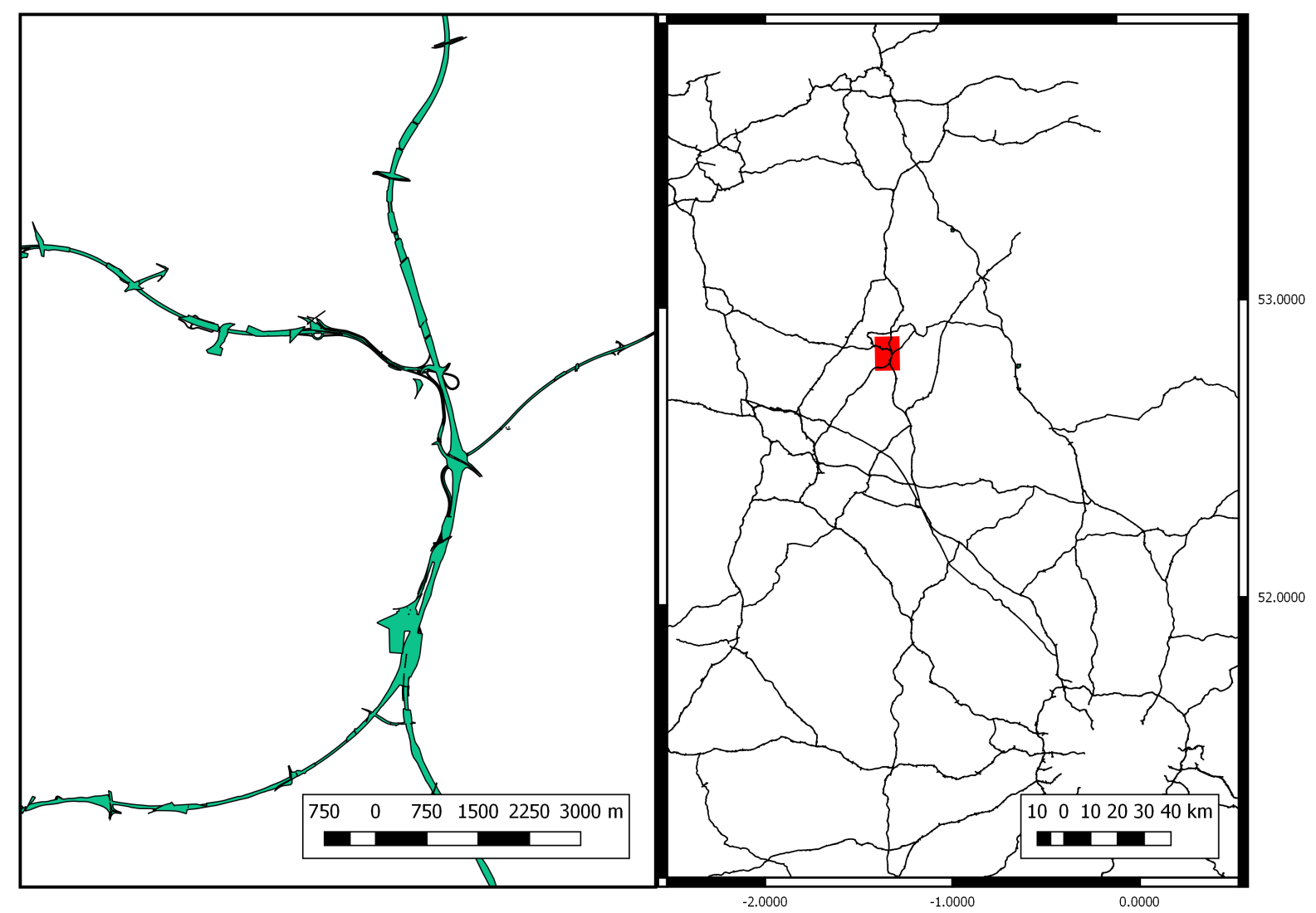

Fig. 1. Highways England Shapefile shown at macro and micro scales. The area in green represents land managed by Highways England.

assumed to be anomalous for journeys on the SRN. The 24 datasets can then be used to generate probability distributions for each hour of the day. The mid point in time for each journey was used to generate the probability distributions since, in the general case, this is the point at which the EV is most likely to be using the SRN and therefore able to use the HREVC.

The Weibull distribution was selected for fitting to these datasets. It is commonly used in failure and reliability analysis. In this use case, the predicted variable $x$ refers to the lifetime of a component allowing a prediction of the "time-to-failure". However, in this work it refers to the point at which the EV journey finished or the "distance-to-end". Therefore, this use of the Weibull distribution can be seen to be appropriate for journey length prediction. This is supported because the Weibull Distribution can have a long tail, which reflects real world journey distance distributions well as high journey distances are relatively common and would not be evident if a gamma or log-normal distribution were chosen. It was decided that the log- 
Fig. 2. Example GPS traces from the Open Street Map shown at 3 scales.

normal distribution was not suitable as it does not represent the varying shape of the distribution of journey distances exhibited in different hours of the day (in particular journeys beginning early in the morning do not follow a log-normal distribution shape). For this feature either the Weibull or Gamma distributions must be used. The gamma distribution assumes an equal chance of a journey termination in each timestep, however the Weibull distribution allows for either increasing or decreasing chances of journey termination as the journey progresses. This feature of the weibull distribution was found to enable a better fit to the journey distances found and also to provide distinction between journeys beginning at different times of the day.

The three parameter Weibull distribution is shown in Equation 1 ;

$$
f(x)=\frac{\gamma}{\alpha}\left(\frac{x-\mu}{\alpha}\right)^{(\gamma-1)} \exp \left(\frac{x-\mu}{\alpha}\right)^{\gamma}
$$

Where: 
Fig. 3. Schematic journey with grey box showing the area which would be assessed for intersection with the SRN shapefile.

- $\gamma$ is the shape parameter.

- $\alpha$ is the scale parameter.

- $\mu$ is the location parameter.

$\mu$ indicates the beginning value of the distribution and is commonly equal to zero i.e. a journey distance of zero at the start of the journey. In this case the Weibull distribution becomes:

$$
f(x)=\frac{\gamma}{\alpha}\left(\frac{x}{\alpha}\right)^{(\gamma-1)} \exp \left(\frac{x}{\alpha}\right)^{\gamma}
$$

This fitting procedure was carried out for each array of journey distances (accounting for each hour of the day) as shown in Figures 4 and 5 . However, despite the size of the original dataset, in the hours 0200-0400, 0500-0600 and 2300-0000 there were not enough journeys to generate a probability distribution $(<5)$.

A $\gamma$ value of $0<\gamma<1$ indicates an increasing probability for a journey to end as the distance increases. A $\gamma$ value of $1<\gamma$ indicates a decreasing probability for a journey to end as the distance increases. It it not surprising then, that, for the majority of the hourly distributions $\gamma$ is less than 1 as drivers are more likely to reach their destination as distance increases. However, for journeys beginning between 2200 and 2300 this is not the case. This parameter of the distributions alone does not reveal the propensity for long distance journeys in each hour though, the scale parameter is needed for this.

The scale parameter $\alpha$ is the mean journey distance. This is not constant through the day. 


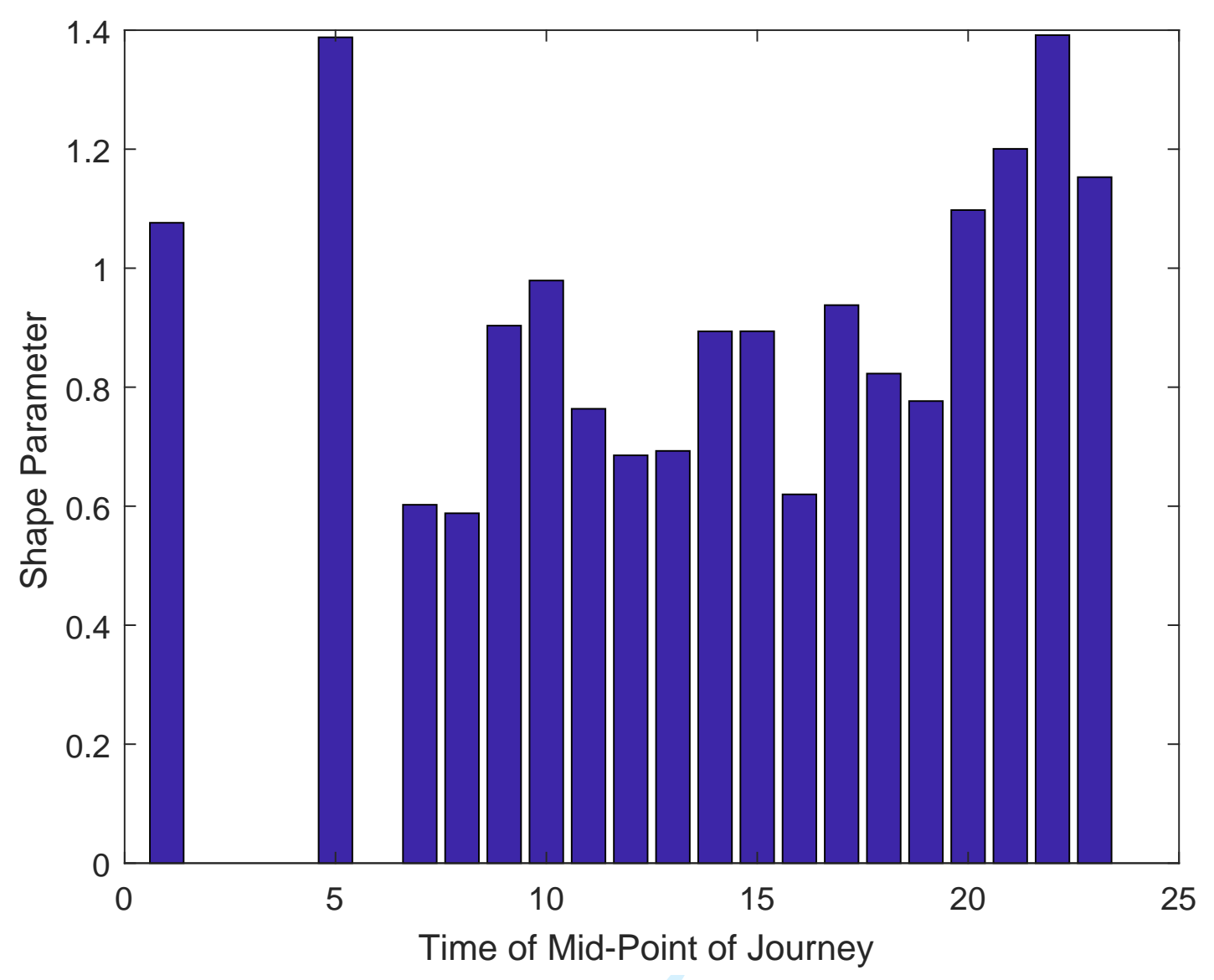

Fig. 4. Weibull Shape parameter for each hour distribution.

In the morning for the hour 0400-0500, a distinctly higher mean journey distance is observed (Figure 5). This could be caused by a preference for long distance, non-routine, journeys to be started in the morning.

This effect is further seen in Figure 6 which shows the probability that a journey will finish by given distances, as calculated from the Weibull Distributions for each hour. For journeys with mid-points between 0400 and 0800 a preference for long distance ( $>100$ mile) can be seen. The hours with the highest probability of short journeys are between 1600 and 1800 with the probability of long journeys beginning in this window becoming small to non-existent. This representation is independent of the frequency with which journeys begin, which is clearly higher during busy periods (see Figure 7). To make a prediction of the number of journeys of a given distance being undertaken at a given time, this analysis must be combined with measured traffic 


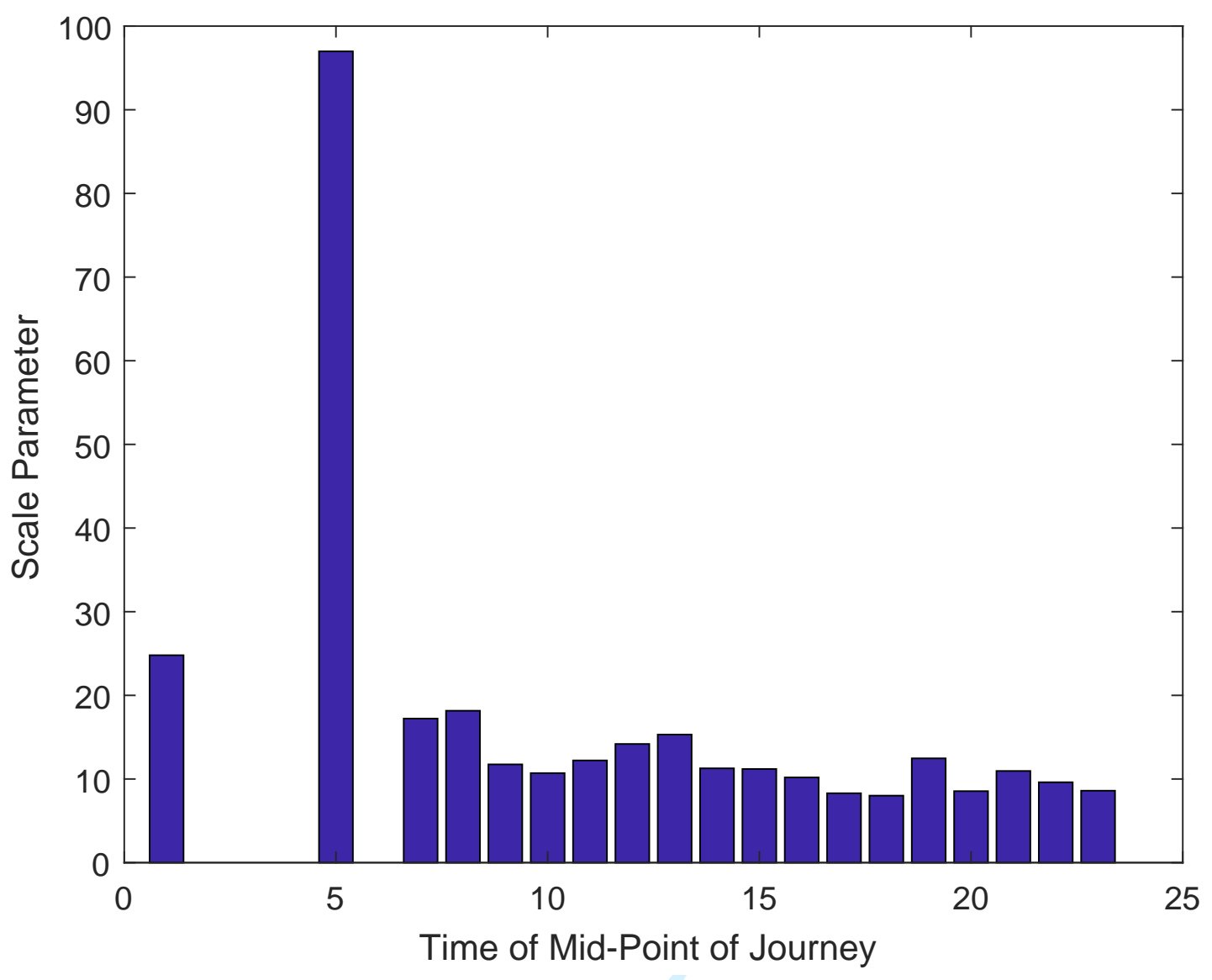

Fig. 5. Mean journey distance against time of day for Weibull Distributions.

flow data.

\section{Including Traffic Flow Data}

The Highways England data repository [30] is a rich source for traffic flow data in the UK. 15 minute resolution vehicle count data can be found for all the roads on the SRN. Additionally, it is possible to select the section of road (between two junctions) at which the traffic flow count is desired. The database is also kept up to date with monthly updates for each road section.

This data resource is used in this work to provide relevant traffic flow data. Indeed, this method of high rate EV demand prediction was designed to be used as a tool with this dataset such that EV demand can be calculated in any location on the SRN.

For this data to be useful in predicting high rate EV demand, the Weibull distance distributions can be utilised with the number of journey distances predicted, using the probability distribution, 
Fig. 6. Cumulative probability of journey distance for each hourly probability distribution.

for each hour, dependent on the measured traffic flow for that hour. This gives a detailed distribution of the number of journeys of certain lengths being undertaken in a given hour. A representation of this analysis is shown in Figure 7. Importantly, the data shown in Figure 7 can be recreated for any point on the SRN by using the traffic flow data for that point.

In order to use this analysis to predict the demand for the HREVC the capacity of the EV battery must first be assessed. This will allow a calculation of the EV range and therefore, whether a HREVC must be used en-route in order to complete the journey. The work covering this analysis is discussed in the following section (Section II-E).

\section{E. EV battery capacity prediction}

An estimation of the distribution of future EV battery capacity $\left(E_{c a p}\right)$ has been formulated from the market share of current vehicle segments. Thiel et al. [31] proposed vehicle segmentation 
Fig. 7. Predicted journey distances for the M25 J15-16.

characteristics as shown in Table [. this follows the segmentation method employed by the European Commission and adopted in the UK. A UK source of this data was sought, however, the inclusion of the mean and standard deviation of engine capacity and mean annual mileage with the market share for each segment led to the selection of this reference for the data source. The market share for each segment of vehicle in the UK is similar to that presented by [32].

As discussed in Section [-B, since the conventional vehicle market is mature, it can be assumed that proportions of each segment of vehicle are likely to remain the same after electrification, specifically, the mean annual mileage and the market share of each segment will remain constant. Therefore, with these assumptions, in order to predict the distribution of $E_{c a p}$ in a future fleet of EVs a prediction must be made for the mean and standard deviation $E_{c a p}$ within each segment. This will differ from the current distribution of EV capacities as the priorities of future EV 
TABLE I

MARKET SHARE OF ICE VEHICLE SEGMENTS IN THE EU IN 2011 [31].

\begin{tabular}{|c|c|c|c|c|c|}
\hline \multirow[t]{2}{*}{ Segment } & \multirow[t]{2}{*}{ Segment Name } & \multirow{2}{*}{$\begin{array}{l}\text { Market Share } \\
(\%)\end{array}$} & \multicolumn{2}{|c|}{ Engine Capacity (l) } & \multirow{2}{*}{$\begin{array}{c}\text { Mean Annual } \\
\text { Mileage }\end{array}$} \\
\hline & & & mean & $\begin{array}{l}\text { standard } \\
\text { deviation }\end{array}$ & \\
\hline A & Mini Cars & 8.7 & 1.12 & 13.4 & 8600 \\
\hline B & Small Cars & 26.0 & 1.34 & 14.5 & 10800 \\
\hline $\mathrm{C}$ & Medium Cars & 23.3 & 1.63 & 22.8 & 13300 \\
\hline $\mathrm{D}$ & Large Cars & 11.0 & 2.02 & 36.4 & 15900 \\
\hline $\mathrm{E}$ & Executive Cars & 3.3 & 2.48 & 59.5 & 17500 \\
\hline $\mathrm{F}$ & Luxury Cars & 0.3 & 3.76 & 97.8 & 13000 \\
\hline $\mathrm{J}$ & Sport Utility Cars & 10.3 & 2.08 & 56.2 & 14000 \\
\hline M & Multi Purpose Cars & 13.1 & 1.66 & 28.2 & 16800 \\
\hline S & Sport Vehicles & 1.3 & 2.45 & 110.3 & 8700 \\
\hline
\end{tabular}

buyers will be different from the current early adopters [33].

In order to use this assumption to generate EV battery capacity distributions a relationship must be sought between a current attribute of the vehicles and $E_{c a p}$, so an equivalent attribute to $E_{c a p}$ in conventional vehicles must be used. Although both the capacity of the fuel tank and $E_{c a p}$ are directly proportional to vehicle range, the cost of the fuel tank is very low and adding additional capacity is relatively easy. This is not the case for $E_{c a p}$ where additional capacity is very costly. Additionally, for the most part, fuel tank capacity is not a primary driver for purchasing decisions in the same way that battery capacity will be [34]. For this reason, the engine capacity is taken as proportional to equivalent $E_{c a p}$.

Whilst at first impression this may seem illogical, a larger battery pack will lead to a greater peak power available from the battery in the same way as a larger engine capacity. Additionally, the sales of each segment of vehicle are largely driven by consumer preferences, in this context, the battery capacity is a primary driver for purchasing decisions in the same way as engine capacity. Indeed, EV manufacturers use the $E_{c a p}$ value for branding (displayed on the body of the EV) in the same way as conventional vehicle manufacturers use engine capacity. This is likely to be due to customer perception that a higher capacity battery correlates to a more capable and expensive vehicle. This assumption is backed up by [34] who conducted a study of 
TABLE II

Classification of CURRENT EVS CAPABlE OF High RATE CHARGING

\begin{tabular}{lcc}
\hline EV Model & $E_{c a p}$ & Segment \\
\hline BMW i3 & $18.8-33.3$ & B \\
Kia Soul EV & 27 & $\mathrm{C}$ \\
Citroen C-Zero & & \\
Mitshubishi i-Miev & 16 & $\mathrm{~A}$ \\
Peugeot iON & & \\
Nissan Leaf & $24-40$ & $\mathrm{C}$ \\
Tesla Model S & $70-100$ & $\mathrm{~F}$ \\
Tesla Model X & 90 & $\mathrm{~J}$ \\
VW E-Up & 18.7 & $\mathrm{~A}$ \\
VW E-Golf & 24.2 & $\mathrm{C}$ \\
\hline
\end{tabular}

the willingness to pay for enhanced features of EVs.

In order to find the relationship between engine capacity and $E_{c a p}$, current EVs are compared to conventional vehicle counterparts. First, these EVs are classified into the European Commission segments, shown in Table II

The ratio $\frac{E_{c a p}}{\text { EngineCapacity }}$ is then found for each segment. There is some variation here due to the immaturity of the EV market. The Tesla vehicles have proportionally larger batteries. The mean of the $\frac{E_{c a p}}{\text { EngineCapacity }}$ ratios for each vehicle segment is calculated to be 21.8. In this paper values of $\frac{E_{c a p}}{\text { EngineCapacity }}$ of 30,40 and 50 are used as these correspond to a growth in the size of batteries installed in EVs consistent with the future scenario assumed.

The probability distribution for $E_{c a p}$ can, therefore, be calculated as the sum of the probability distributions for each segment as shown in Equation 3. The probability density function for each vehicle segment is scaled to the proportion of total miles driven by that segment. This is achieved by multiplying each segment by the market share and mean annual mileage for that segment. A lognormal distribution is assumed for each vehicle segment since a normal distribution is adopted in this work, but zero or negative values of $E_{c a p}$ do not make sense, and so attenuation of the probability of small values of $E_{c a p}$ is useful.

$$
P D F_{E_{c a p}}=\sum_{A=i}^{S} M_{i} \cdot Y_{i} \cdot \frac{1}{\sigma_{i} \sqrt{2 \pi}} e^{\frac{-\left(E_{c a p}-\left(\mu_{i} \times 21.8\right)\right)^{2}}{2 \sigma_{i}^{2}}}
$$

Where: 
- $M$ is the market share

- $Y$ is the normalised annual mileage

- $i$ is the vehicle segment

- $S$ is the no. of vehicle segments

- $\mu$ is the mean battery capacity

- $\sigma$ is the standard deviation of battery capacities

The probability density function for each vehicle segment is shown in Figure 8 , The two vehicle segments which have the largest impact on the overall probability density function are $\mathrm{B}$ and $\mathrm{C}$, this is mainly due to the higher market share of these vehicles. Conversely, the $\mathrm{S}$ and F segments have very little contribution to the overall probability density function since their market share is low. It should be noted that this is not what is currently seen in the EV market, as it is distorted by an over-sized luxury segment due to the popularity of the Tesla model S. This is predicted to change as the market grows and adopts the more established purchasing norms and will reflect more closely the analysis shown here.

The sum of the probability density functions for each segment is shown in Figure 8 . The $\frac{E_{\text {cap }}}{\text { EngineCapacity }}$ figure of 21.8 used in Figure 8 is derived from EVs currently available. However, as the price of lithium-ion batteries is subject to further reductions [35], this is likely to change. It is expected that this factor will increase in this case and Figure 9 shows the effect of this change in the future. The peaks for each vehicle segment become distinct and $E_{c a p}$ covers a wider range. By varying the value of this factor, future cases can be analysed.

\section{F. Running the Stochastic Simulation}

The relevant parameters for calculating the charge profile for the EV are the EV battery capacity, the initial SOC and the final SOC. As such, the use of the probability density functions must result in relevant predictions of these parameters. Additionally, the time at which a charge instance begins is also a key output. These parameters are calculated as follows:

By generating random numbers from the distributions discussed in Sections II-B and II-E the following parameters are found for each $\mathrm{EV}$ :

- $D$ - Journey distance (miles)

- $T_{\text {Start }}$ - Journey start time

- $E_{c a p}$ - EV battery capacity in kWh. 


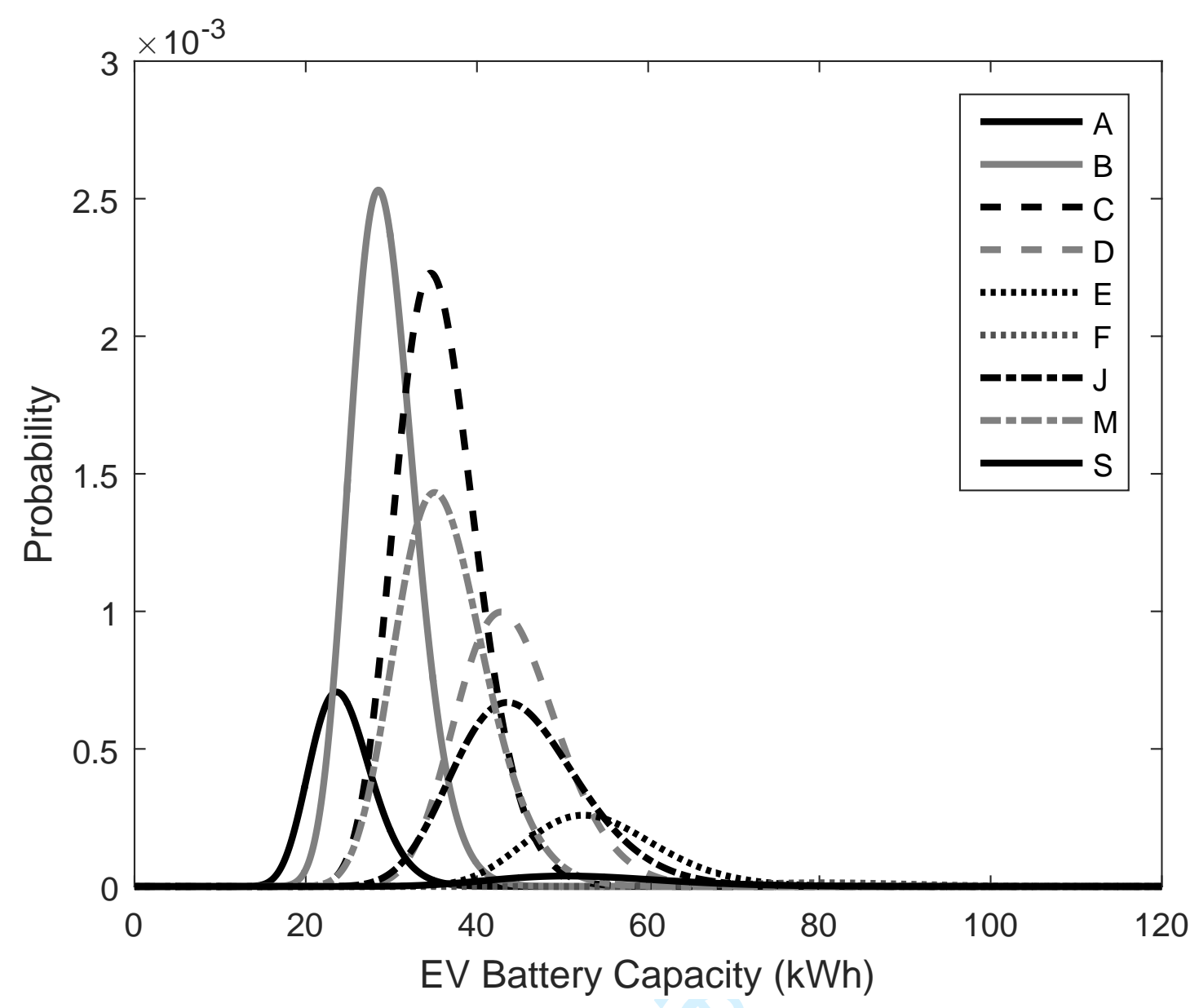

Fig. 8. Probability density functions for $E_{c a p}$ for each segment of car.

The range of the EV is then calculated:

$$
R=E_{\text {cap }} \times W_{\text {avg }}
$$

Where $W_{\text {avg }}$ is the number of miles which can be driven for each $\mathrm{kWh}$ or stored energy (miles/kWh) and $R$ is the range in miles. If the Range is less than the journey distance then a HREVC must be used. For EVs where the range exceeds the journey distance, the HREVC is not needed and therefore no further calculation is required. For the journeys where a HREVC use is required two pertinent questions now arise: Firstly, at what distance in the journey will the HREVC use be required? And secondly, at what time will this arise?

To find the distance firstly, a mesh of potential HREVC locations is created, each 28 miles apart (see Table III) with the first being a random number in the range $0<X<28$. The selected 
Fig. 9. The effect of varying $\frac{E_{\text {cap }}}{\text { EngineCapacity }}$ on the probability density function for $E_{c a p}$ for the sum of all segments.

HREVC is then the last feasible station prior to the EVs SOC reaching zero:

$$
\begin{aligned}
& \text { if } D>R \\
& n=\text { floor }\left(\frac{R-X}{28}\right)
\end{aligned}
$$

Where:

- $n$ is the HREVC number

- $X$ is a random number in the range $0<X<28$

$$
H R E V C_{d i s t}=X+28 n
$$

Where $H R E V C_{\text {dist }}$ is the distance to the selected HREVC from the journey start point in miles. Thus, we have the distance after beginning the journey at which the HREVC use will 
arise, so now we need to consider the journey timing. The distance to the HREVC is divided by the mean speed ( $V_{E V}$, see Table III) and that time is then added to the journey start time $\left(T_{\text {start }}\right)$.

$$
T_{\text {charge }}=T_{\text {start }}+\left(\frac{H R E V C_{\text {dist }}}{V_{E V}}\right)
$$

The state of charge at the HREVC $\left(S O C_{i n i}\right.$ ) can then be found by dividing the energy used to get to the selected HREVC by the energy capacity of the EV.

$$
S O C_{i n i}=\left(\frac{H R E V C_{d i s t} / W_{a v g}}{E_{c a p}}\right)
$$

This process is repeated for up to $3 \mathrm{HREVC}$ uses per journey (it is assumed that more stops than this would lead to journey distances longer than is feasible in the UK ( $\approx 500$ miles)).

1) Assumptions: These calculations use a number of numerical assumptions. They are detailed in Table III,

TABLE III

\begin{tabular}{|c|c|c|}
\hline Variable & Value & Justification \\
\hline $\begin{array}{c}\mathrm{EV} S O C \text { at the start } \\
\text { of the journey }\end{array}$ & $1=100 \%$ & $\begin{array}{l}\text { Overnight charging is the } \\
\text { main form of EV charging. This } \\
\text { leads to an EV beginning each } \\
\text { journey with full charge. }\end{array}$ \\
\hline Mean Speed $\left(V_{E V}\right)$ & $48 \mathrm{mph}$ & $\begin{array}{l}\text { Quoted mean speed in } \\
\text { Free Flow Vehicle Speed Statistics: } \\
\text { Great Britain } 2015 \\
\text { |36|. }\end{array}$ \\
\hline Distance between HREVCs & 28 miles & $\begin{array}{l}\text { This is set as a target for spacing } \\
\text { of services in Department for } \\
\text { Transport Circular 01/2008 } \\
\text { 37]. }\end{array}$ \\
\hline EV Energy Use $\left(P_{a v g}\right)$ & 3 miles/kWh & Conservative estimate from [38]. \\
\hline
\end{tabular}

ASSUMPTIONS USING IN THE CALCULATION OF THE HREVC USE PARAMETERS.

2) EV charge calculations: The energy demand per charge instance is dependent on the EV battery capacity, the initial SOC and the final SOC. Therefore the energy transferred to an EV 
utilising the HREVC can be given by Equation 9 .

$$
E_{\text {trans }}=E_{\text {cap }} \times\left(S O C_{f i n}-S O C_{i n i}\right)
$$

Where:

- $E_{\text {trans }}$ is the energy transferred to the EV $(\mathrm{kWh})$ from the HREVC

- $E_{c a p}$ is the battery capacity of the EV $(\mathrm{kWh})$

- $S O C_{i n i}$ and $S O C_{\text {fin }}$ are the initial and final SOCs of the EV battery when arriving and leaving the HREVC respectively (0-1).

As such, the three variables; $E_{c a p}, S O C_{i n i}$ and $S O C_{f i n}$ are key to predicting the power demand of the HREVC since they control the overall energy transferred to the EV and the power profile during the charging process.

The temporal change in power demand over the duration of an EV charge has been derived from Tesla Supercharger power data. This is shown in equation 10.

The charge demand for each EV can be split into two stages, the first is given by maximum charge power $\left(P_{\max }\right)$ and increased the SOC to a value of 0.22 . The second stage increases the SOC from 0.22 to 1 with diminishing power following a relationship derived from Tesla Supercharger curves [39]. Equation 10 shows how the power to the EV changes as a function of SOC.

$$
P(t)= \begin{cases}P_{\max } & 0<S O C(t)<0.22 \\ P_{\max } e^{(-k \cdot 0.22))} & 0.22 \leq S O C(t)<1\end{cases}
$$

With SOC changing as a function of energy transferred and battery capacity, as shown in Equation 11 .

$$
S O C(t)=\frac{\int_{0}^{t} P(t) d t}{E_{c a p}}
$$

Solving Equations 10 and 11 yields Equation 12 , where $S O C(t)$ is expressed solely as a function of $P_{\max }$ and $E_{\text {cap }}$ :

$$
S O C(t)=\frac{\ln \left(-k\left(C-\frac{P_{\max } \cdot t}{E_{c a p}}\right)\right)}{k}
$$

Where:

- $k$ is the exponential decay constant of power with respect to SOC. 
- $C$ is the integration constant found using initial conditions.

For this simulation a future situation is considered where EV batteries have an increased ability to accept fast charging. Therefore $P_{\max }$ is set to $300 \mathrm{~kW}$. It is more difficult to predict a value for $k$, as a smaller value of $k$ would result in a quicker overall charge, however, this may not be achievable within the constraints of a future EV battery. In this simulation, $k$ is set to 2.0, the same as is currently observed within the Tesla Supercharger profiles.

A sample EV charge demand profile is shown in Figure 10.

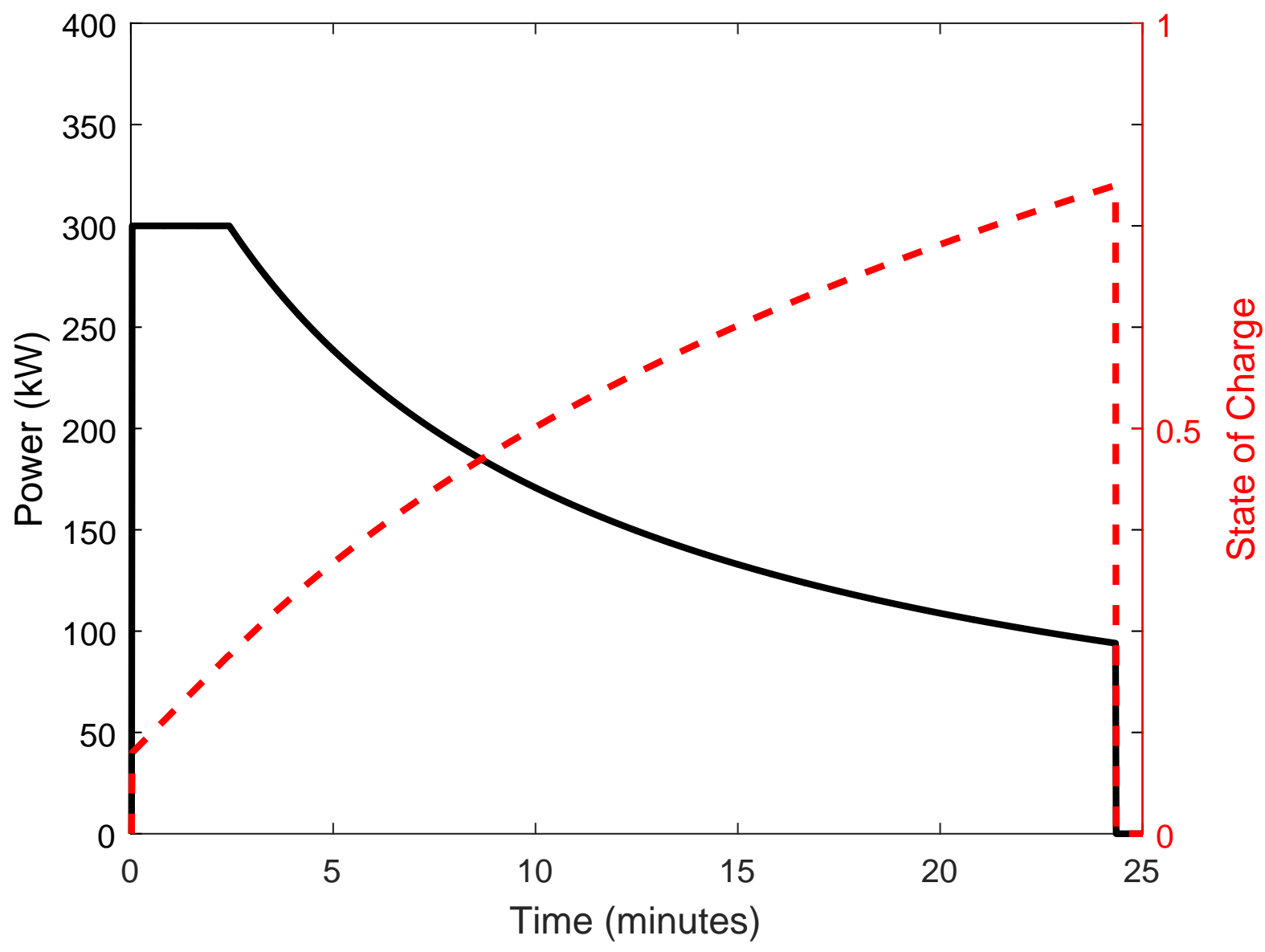

Fig. 10. Power demand for a single EV with $E_{c a p}=100 \mathrm{kWh}, P_{\max }=300 \mathrm{~kW}, S O C_{i n i}=0.1, S O C_{f i n}=0.8$ and $k=2.0$

\section{CAse Study}

In order to generate these example results, traffic flow data from 3 motorways in the UK were used. These are highly utilised roads and are therefore locations likely to require HREVC 
TABLE IV

EFFECT OF EV BATTERY SIZE ON HREVC USE FOR 10\% EVS AT THE M25 J15-16.

\begin{tabular}{ccc}
\hline EV Battery Capacity Factor & Mean No. HREVC Uses / day & Mean Total Energy (MWh) \\
\hline 30 & 58.8 & 2.40 \\
40 & 27.8 & 1.47 \\
50 & 13.6 & 0.89 \\
\hline
\end{tabular}

installations. The motorways selected are the M25, the main circular motorway around London, the M3 and the M4. The location on these motorways is indicated by the numbers of the junctions the measurement point lies between (i.e. J15-16).

\section{A. Effect of EV Battery Size}

The effect of different EV battery size scenarios is shown in Figure 11 where the probability of HREVC use for each hour of the day is plotted for $3 \mathrm{EV}$ capacity factors $(30,40,50)$.

Due to the tendency for long journeys to be started in the morning (as seen in Figure 6), a peak in demand is seen in the late morning. This is in contrast to the predictions made in the literature; if the demand is assumed to be proportional to traffic flow, two peaks are seen, one in the morning and one in the evening. However, as is shown in Figure 11, the journeys which are long enough to result in a HREVC use tend to begin in the morning and lead to a high demand for charging in the middle of the day. After this peak, demand diminishes through the rest of the day. This reduction in demand after the initial peak is due to the increasing probability that a given journey will finish as its distance increases, thus additional HREVC use is increasingly unlikely.

Larger EV batteries (higher EV capacity factors) lead to a later HREVC demand due to the increasing range leading to longer journey times before needing an HREVC charge. Additionally, the overall number of charges (Table IV) is reduced through increasing EV battery capacity factor as the probability of the range of the EV being sufficient to power the entire journey increases. The predicted total energy transferred to EVs also diminishes with higher EV battery capacities due to fewer charging instances. 


\section{B. Effect of HREVC Location}

An EV demand pattern for an HREVC can now be generated stochastically for any location on the SRN in the UK. Three locations have been selected for illustration purposes, these are shown in Table $\mathrm{V}$, additionally, the traffic flow patterns for these locations is shown in Figure 12 . To populate the data in Table $\mathrm{V}$, the simulation was repeated ten times to achieve mean values with an EV penetration value of $10 \%$. Clearly, when there is a higher level of traffic flow over a road, the HREVC is utilised more. Curiously though, the percentage of vehicles using the HREVC is not constant. In the examples studied here, it varies between $0.5-0.7 \%$ of EVs.

The cause of this variation lies in the difference in shape of the traffic flow patterns. The M3 and M4 motorways have higher percentage of HREVC use due to a higher proportion of the journeys occurring in the morning. Likewise, the M25 has sustained high traffic flow levels throughout the day, thus, a lower proportion of journeys occur in the morning leading to lower overall percentage HREVC use on the M25 as shown in Figure 12. 
TABLE V

EFFECT OF LOCATION ON NUMBER OF USES PER DAY OF THE HREVC WITH AN EV CAPACITY FACTOR OF 30 AND AN EV PENETRATION OF $10 \%$.

\begin{tabular}{cccc}
\hline Location & Total Traffic Flow & Mean HREVC Uses / day & Percentage Use (EVs) \\
\hline M25 J15-16 & 112675 & 58.8 & 0.52 \\
M4 J17-18 & 45474 & 31.4 & 0.69 \\
M3 J13-14 & 64393 & 43.2 & 0.67 \\
\hline
\end{tabular}

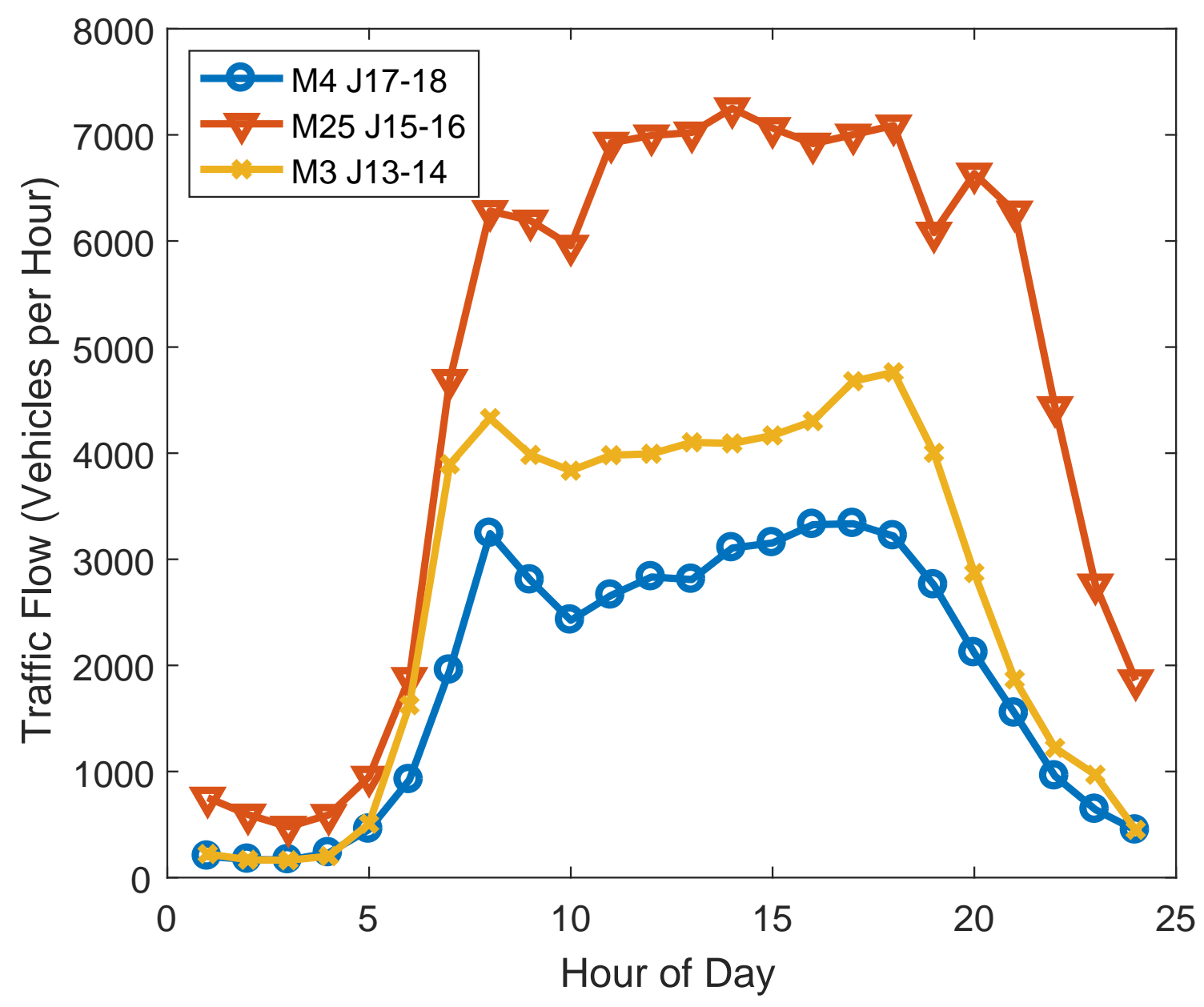

Fig. 12. Traffic flow measurements for 3 motorway locations in the UK. 
Using traffic flow data for different locations on the SRN, an HREVC demand pattern can be generated for each of them. An example of this is shown in Figure 13. For these simulations, the number of EVs was assumed to be $10 \%$ of the overall traffic flow, the peak power for each EV was $300 \mathrm{~kW}$ and the EV battery factor was 30. Of these EVs, $0.5-0.75 \%$ required an HREVC to complete the required journey. The main difference in the demand, arising from simulating different HREVC locations, is the difference in magnitude. There is more traffic flow on the M25, which results in higher HREVC demand.

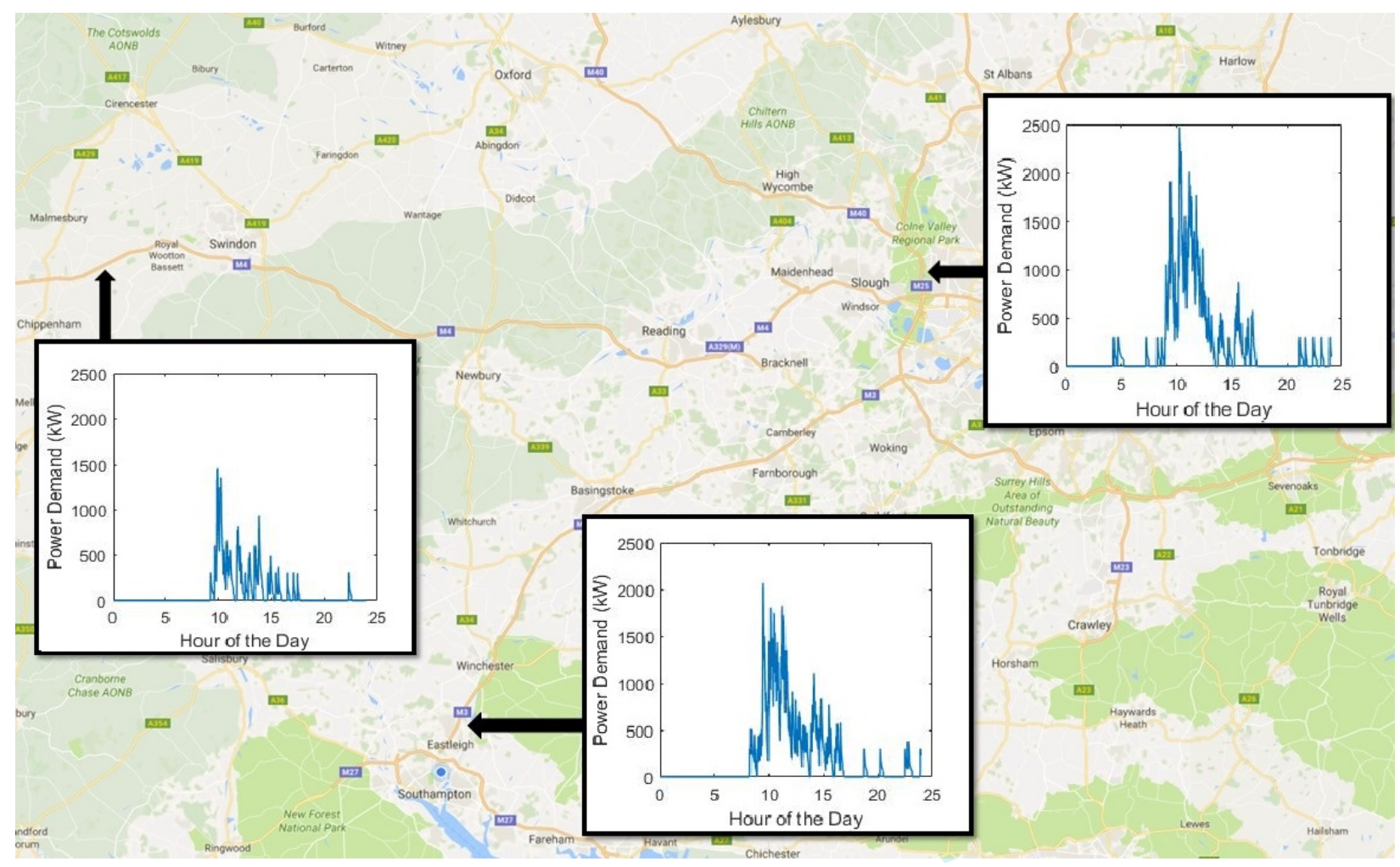

Fig. 13. HREVC demand stochastically generated for three locations in the UK from traffic flow data available for that location, assuming an EV penetration of $10 \%$.

\section{Discussion}

This method uses existing travel data sources in the UK and adds to them through the information gathered in the Open Street Map GPS track dump, so it is incompatible to compare the results from this analysis to those statistics. However, when comparing the HREVC use patterns found to those in the literature, some differences are seen. The HREVC demand patterns found in this paper exhibit a greater tendency to have high demand levels in the early afternoon 
than other methods used in the literature. This effect is partly due to the nature of the data extracted from the open street map and partly due to the novel methods presented. This method does not rely solely on traffic flow measurements which gives a tendency to produce an HREVC demand pattern with two peaks, each aligned with the times of high road use. A single peak in HREVC demand is predicted here which aligns with other methods which do not assume proportionality with traffic flow, such as the work by Simpson et al [20]. Contrasting the previous methods which do not assume proportionality to traffic flow to this work, an earlier peak in demand is predicted here. This is due to the travel patters observed in the Open Street Map GPS trace dump. A tendency for long journeys to begin in the morning was observed. As this data has not been previously used for similar work it is not surprising that there are differences in the outcomes. The journey information extracted from the open street map relates solely to main roads in the UK, it is therefore an important consideration for future planning decisions that demand on these roads may be different to that generally seen in literature from around the world.

This method allows for locationally dependant predictions of HREVC demand. This will enable informed planning of HREVCs on the SRN. Whilst a general increase in HREVC demand can be expected with roads with higher traffic flow, the characteristics of that traffic flow are also important in predicting HREVC demand. A higher than average traffic flow in the morning will result in a more distinct peak in HREVC demand, whilst HREVC demand which is more consistent through the day is seen on roads which have lower than average demand in the morning. Understanding this effect and its dependence on location is important in HREVC design as a demand with a distinct peak will need greater power availability and a larger number of charge points than one with a sustained demand pattern through the day (assuming the same overall charger usage).

The assumption that EV SOCs are equal to 1 at the start of the day will not hold for all cases. Specifically, the low power levels available in a domestic setting may not be capable of returning an EV with large battery capacity to full SOC within the duration of overnight parking. Therefore there may be additional uses of an HREVC, by owners of EVs with high battery capacities, to compensate for this which are not predicted in this paper. Additionally, there may be usage of the HREVC which are not related to long journeys in the way presented, such as charging in preparation for a journey at a later time. There are inevitably many factors such as these which may, or may not, affect the use of HREVCs which a predictive tool such as that proposed in 
this work is unlikely to sufficiently represent, however it is important to be aware of them and of the potential effect on the charging pattern they may have.

The choice of the Weibull distribution may lead to an under-reporting of the overall number of charges per journey due to over estimation of short journeys ( $<1 \mathrm{mile}$ ) which do not lead to an HREVC charge. However, the improved fit with longer distance journeys which is enabled by use of the weibull distribution leads to greater accuracy of the prediction. For this reason, over estimation of short journeys is likely equalled by under estimation of medium length journeys, leaving long journeys accurately represented. This is enabled through varying the rate at which the probability of journey finish varies with respect to the journey distance (by varying the shape factor) and a preference for accurate fitting of the tail of the distribution. This effect was important as accurate predictions of long distance journeys are clearly the priority of this work.

This work enables improved accuracy of HREVC power demand predictions, both at the current time and for the future. It has also opened the possibility of analysis of the role HREVC power demand can potentially play in the wider energy system. For example, an earlier peak in HREVC demand, as is suggested here has the potential to offset grid imbalances caused by increasing solar power generation. So, this work has wider implications than those of just HREVC design.

\section{Conclusions}

A novel method for predicting EV demand at HREVCs has been presented. Critically, this predicts HREVC demand in the UK, using data arising from the UK to find travel patterns on main roads, in a locationally dependent way. HREVC demand can be predicted for varying locations in the UK by using traffic flow measurements from that location. The method for predicting future EV battery capacities is also presented.

The key advantages of the method presented in this paper are:

- The HREVC demand prediction method is locationally dependent, and as such the expected HREVC demand can be generated for any location on the SRN. This is crucial for selecting specific sites when planning an HREVC.

- The prediction is based on open source data which has not been used for similar studies before. This data accurately describes movement patterns for many aspects of life and a data mining approach has been used to identify relevant journeys. This reduces the need for costly and time consuming studies using vehicle trackers. 
- The method is not based on the current fleet of EVs which is currently limited and not representative of a market which reflect the desires of the consumer. Instead, a method for predicting EV battery capacity which uses current conventional vehicles segments is proposed. This allows for HREVC demand planning for a future scenario.

A case study is then included which assesses the HREVC demand at 3 locations on motorways in the UK.

This work is useful for the planning of an HREVC network. The method presented in this paper is novel and the Open Street Map dataset has not been previously used for a similar application. This work, therefore, provides a framework for assessing EV demand in order to design and implement an HREVC network for the future. Furthermore, this analysis enables the role of HREVCs in the wider energy system to be assessed and optimised.

The quantity of data available from the Open Street Map is expected to grow and is not confined to the UK. Therefore, this method has value which will grow and is relevant across the world.

Further work should look into the two assumptions highlighted in Section $[-B$ as it is unknown at present the role of psychological factors and the degree of similarity between movements conducted in EVs and conventional vehicles and what effect these may have on HREVC use.

\section{ACKNOWLEDGMENT AND DATA AVAILABILITY}

This work was supported by the UK Engineering and Physical Science Research Council (EPSRC) under Grant (EP/L016818/1) and Grant (EP/M009394/1).

The authors would also like to thank the Open Street Map contributors.

All other data and models supporting this study are openly available from the University of Southampton repository at http://doi.org/10.5258/SOTON/XXXX.

\section{REFERENCES}

[1] World Health Organization and others, "Ambient air pollution: a global assessment of exposure and burden of disease," in Ambient air pollution: a global assessment of exposure and burden of disease, 2016.

[2] M. Åhman, "Primary energy efficiency of alternative powertrains in vehicles," Energy, vol. 26, no. 11, pp. 973-989, 2001.

[3] W. Ke, S. Zhang, X. He, Y. Wu, and J. Hao, "Well-to-wheels energy consumption and emissions of electric vehicles: Mid-term implications from real-world features and air pollution control progress,” Applied Energy, vol. 188, pp. 367-377, 2017. 
1

2

3

4

5

6

7

8

9

[4] J. Neubauer and E. Wood, "The impact of range anxiety and home, workplace, and public charging infrastructure on simulated battery electric vehicle lifetime utility," Journal of Power Sources, vol. 257, pp. 12 - 20, 2014. [Online]. Available: http://www.sciencedirect.com/science/article/pii/S0378775314000998

[5] V. del Razo and H.-A. Jacobsen, "Smart charging schedules for highway travel with electric vehicles," IEEE Transactions on Transportation Electrification, vol. 2, no. 2, pp. 160-173, 2016.

[6] Z. Moghaddam, I. Ahmad, D. Habibi, and Q. V. Phung, "Smart charging strategy for electric vehicle charging stations," IEEE Transactions on Transportation Electrification, 2017.

[7] C. J. Sheppard, A. Harris, and A. R. Gopal, "Cost-effective siting of electric vehicle charging infrastructure with agent-based modeling," IEEE Transactions on Transportation Electrification, vol. 2, no. 2, pp. 174-189, 2016.

[8] M. Haklay and P. Weber, “Openstreetmap: User-generated street maps," IEEE Pervasive Computing, vol. 7, no. 4, pp. 12-18, 2008.

[9] Tesla Motors Inc. (2017) Tesla Motors Inc. [Online]. Available: http://www.teslamotors.com/en

[10] R. Abousleiman and R. Scholer, "Smart charging: System design and implementation for interaction between plug-in electric vehicles and the power grid," IEEE Transactions on Transportation Electrification, vol. 1, no. 1, pp. 18-25, 2015.

[11] Y.-T. Liao and C.-N. Lu, "Dispatch of ev charging station energy resources for sustainable mobility," IEEE Transactions on Transportation Electrification, vol. 1, no. 1, pp. 86-93, 2015.

[12] C. Le Floch, F. Belletti, and S. Moura, "Optimal charging of electric vehicles for load shaping: A dual-splitting framework with explicit convergence bounds," IEEE Transactions on Transportation Electrification, vol. 2, no. 2, pp. 190-199, 2016.

[13] Y. Ma, T. Houghton, A. Cruden, and D. Infield, "Modeling the benefits of vehicle-to-grid technology to a power system," Power Systems, IEEE Transactions on, vol. 27, no. 2, pp. 1012-1020, 2012.

[14] Department for Transport. (2016) National travel survey.

[15] H. Höimoja, M. Vasiladiotis, and A. Rufer, "Power interfaces and storage selection for an ultrafast ev charging station," in Power Electronics, Machines and Drives (PEMD 2012), 6th IET International Conference on. IET, 2012, pp. 1-6.

[16] M. Tsirinomeny, H. Hõimoja, A. Rufer, G. Dziechciaruk, and A. Vezzini, "Optimizing ev driving-recharge time ratio a under limited grid connection," in Power Electronics, Machines and Drives (PEMD 2014), 7th IET International Conference on. IET, 2014, pp. 1-6.

[17] G. Mauri and A. Valsecchi, "Fast charging stations for electric vehicle: The impact on the mv distribution grids of the milan metropolitan area," in Energy Conference and Exhibition (ENERGYCON), 2012 IEEE International. IEEE, 2012, pp. 1055-1059.

[18] K. Yunus, H. Z. De La Parra, and M. Reza, "Distribution grid impact of plug-in electric vehicles charging at fast charging stations using stochastic charging model," in Power Electronics and Applications (EPE 2011), Proceedings of the 2011-14th European Conference on. IEEE, 2011, pp. 1-11.

[19] National Renewable Energy Laboratory. (2017) Transportation secure data center.

[20] M. Simpson and T. Markel, "Plug-in electric vehicle fast charge station operational analysis with integrated renewables," in International Battery, Hybrid and Fuel Cell Electric Vehicle Symposium, vol. 26, 2012.

[21] N. S. Pearre, W. Kempton, R. L. Guensler, and V. V. Elango, "Electric vehicles: How much range is required for a days driving?" Transportation Research Part C: Emerging Technologies, vol. 19, no. 6, pp. 1171-1184, 2011.

[22] M. Khan and K. M. Kockelman, "Predicting the market potential of plug-in electric vehicles using multiday gps data," Energy Policy, vol. 46, pp. 225-233, 2012.

[23] Open Street Map. (2017, Feb)

[24] T. F. Golob and J. Gould, "Projecting use of electric vehicles from household vehicle trials," Transportation Research Part B: Methodological, vol. 32, no. 7, pp. 441-454, 1998. 
[25] A. Lojowska, D. Kurowicka, G. Papaefthymiou, and L. van der Sluis, "Stochastic modeling of power demand due to evs using copula," IEEE Transactions on Power Systems, vol. 27, no. 4, pp. 1960-1968, 2012.

[26] J. D. Kim and M. Rahimi, "Future energy loads for a large-scale adoption of electric vehicles in the city of los angeles: Impacts on greenhouse gas (ghg) emissions," Energy Policy, vol. 73, pp. 620-630, 2014.

[27] M. De Gennaro, E. Paffumi, G. Martini, and H. Scholz, "A pilot study to address the travel behaviour and the usability of electric vehicles in two italian provinces," Case studies on transport policy, vol. 2, no. 3, pp. 116-141, 2014.

[28] M. Muratori, M. J. Moran, E. Serra, and G. Rizzoni, "Highly-resolved modeling of personal transportation energy consumption in the united states," Energy, vol. 58, pp. 168-177, 2013.

[29] H. England. (2016, June) Highway boundary.

[30] Highways England. (2017, March) Traffic flow data.

[31] C. Thiel, J. Schmidt, A. Van Zyl, and E. Schmid, "Cost and well-to-wheel implications of the vehicle fleet co 2 emission regulation in the european union," Transportation Research Part A: policy and practice, vol. 63, pp. 25-42, 2014.

[32] The Society of Motor Manufacturers and Traders. (2017) Smmt vehicle data.

[33] J. Axsen, S. Goldberg, and J. Bailey, "How might potential future plug-in electric vehicle buyers differ from current pioneer owners?" Transportation Research Part D: Transport and Environment, vol. 47, pp. 357-370, 2016.

[34] M. K. Hidrue, G. R. Parsons, W. Kempton, and M. P. Gardner, "Willingness to pay for electric vehicles and their attributes," Resource and Energy Economics, vol. 33, no. 3, pp. 686-705, 2011.

[35] B. Nykvist and M. Nilsson, "Rapidly falling costs of battery packs for electric vehicles," Nature Climate Change, vol. 5, no. 4, pp. 329-332, 2015.

[36] Department for Transport. (2015) Free flow vehicle speed statistics: Great britain.

[37] — - "Policy on service areas and other roadside facilities on motorways and all purpose trunk roads in england," apr 2008.

[38] X. Wu, D. Freese, A. Cabrera, and W. A. Kitch, "Electric vehicles energy consumption measurement and estimation," Transportation Research Part D: Transport and Environment, vol. 34, pp. 52-67, 2015.

[39] T. S. Bryden, A. J. Cruden, G. Hilton, B. H. Dimitrov, C. P. de Leon, and A. Mortimer, "Off-vehicle energy store selection for high rate ev charging station," in 6th Hybrid and Electric Vehicles Conference (HEVC 2016), Nov 2016, pp. 1-9.

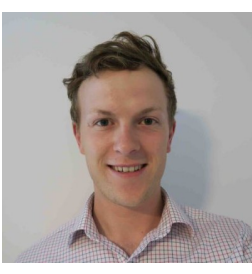

George Hilton George Hilton is a $\mathrm{PhD}$ student at the University of Southampton, where he is part of the EPSRC Centre for Doctoral Training in Energy Storage. Prior to becoming a PhD student George graduated from Southampton University in 2014 with a Masters in Mechanical Engineering. George is focusing on the integration of renewable energy into a high rate electric vehicle charger. This is made possible through energy storage within the charging system. His work is looking to find an optimal design of such a system within the UK grid restraints. 
1

2

3

4

5

6

7

8

9

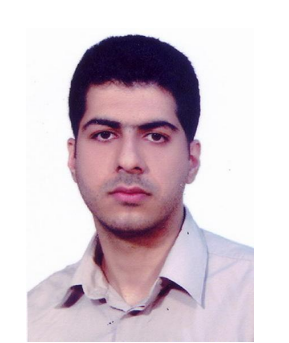

Mahdi Kiaee Dr Mahdi Kiaee is a Research Fellow in the Energy Technology Research Group within Engineering and the Environment at the University of Southampton.

Previously, Mahdi worked on a project entitled Battery Characterisation and Management âAŞ̧ the key to Smart Grids and the Integration of EVs. The project studied lithium battery cell development and Vehicle to Grid (V2G) operation to investigate grid scale energy storage. Mahdi was also involved in some management roles of that project. He is currently working on characterisation of storage devices and their optimal integration in the electric power system with significant penetration of intermittent renewable power as a part of a project supported by Joint UK-India Clean Energy Centre (JUICE).

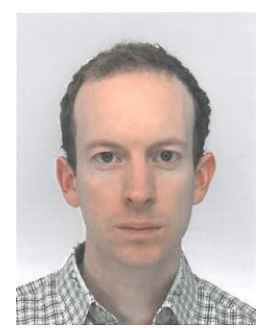

Thomas Bryden Thomas Bryden is a PhD student at the University of Southampton, where he is part of the EPSRC Centre for Doctoral Training in Energy Storage. Prior to becoming a PhD student Thomas graduated from Warwick University in 2011 with a Masters in Mechanical Engineering before joining a Subsea Engineering Consultancy where he worked as an Engineer for 3 years. Thomas is focusing on the potential type and size of the off-vehicle energy store at the fast charging station. To specify the optimum off-vehicle energy store Thomas will be investigating: Future high rate EV charging capability; Capabilities and costs of energy stores suitable for use as the off-vehicle energy store; Future fast charging usage; Grid impacts of high power connections.

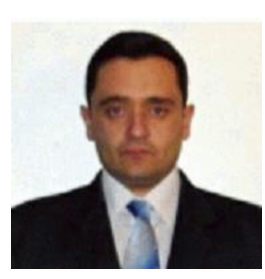

Borislav Dimitrov Dr. Borislav Dimitrov is a Research Fellow within the Energy Technology Group at the University of Southampton. He has experience in the fields of power electronics and microcontroller systems.

Borislav Dimitrov received his $\mathrm{PhD}$ in Electrical Engineering from Technical University of Varna, Bulgaria. After completion of his $\mathrm{PhD}$, he worked for the same University as researcher and lecturer. $\mathrm{He}$ has joined Southampton University as a research fellow in Jan 2016.

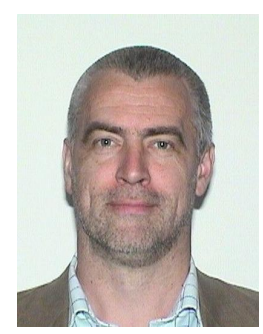

Andrew Cruden Professor Andrew Cruden is Professor of Energy Technology within Engineering and the Environment at the University of Southampton.

Prof Andrew Cruden obtained his BEng, MSc and PhD degrees in Electronic and Electrical Engineering from the University of Strathclyde, Glasgow, in 1989, 1990 and 1998, respectively. He had a range of research posts at Strathclyde until 1998 when he was appointed Lecturer, then promoted to Senior Lecturer in 2004 and Reader in 2010. He was appointed as Professor of Energy Technology at the University of Southampton in July 2012, within the Electro-Mechanical Research Group. In July 2013, he took up the role of Head of the Energy Technology Research Group. He is a Chartered Engineer. 
Alan Mortimer Alan Mortimer graduated from Glasgow University in 1987 with an Honours degree in

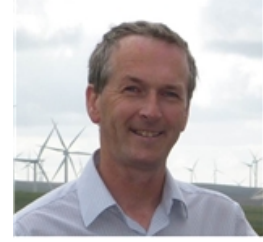
Aeronautical Engineering. After four years at James Howden Co. Ltd. in Glasgow, Alan joined ScottishPower. His roles included Head of Wind Development where he developed the strategy for, and led the development of a wind portfolio including Whitelee Windfarm. Alan was subsequently responsible for managing policy and strategic issues and this included SPRs role in technology development programmes such as the Offshore Wind Accelerator, and marine renewables. He identified and led the development the 10MW Islay Tidal Demonstration Array project. He has managed activities to develop the marine supply chain to maximise Scottish content. Alan joined SgurrEnergy in 2013 as Director of Innovation where his role involves extending the companys renewable energy activities in onshore wind, offshore wind, solar, wave, tidal, heat and transport. This includes managing SgurrEnergys wind farm Optimiser programme, enhancing the performance and value of wind farm assets globally. 